Prepared for the U.S. Department of Energy

under Contract DE-AC05-76RL01830

\title{
Summary of the Preliminary Optical ICHMI Design Study: A Preliminary Engineering Design Study for a Standpipe Viewport
}

NC Anheier Jr

H Qiao
EJ Berglin

BK Hatchell

December 2013

Pacific Northwest

NATIONAL LABORATORY

Proudly Operated by Battelle Since 1965 


\title{
DISCLAIMER
}

This report was prepared as an account of work sponsored by an agency of the United States Government. Neither the United States Government nor any agency thereof, nor Battelle Memorial Institute, nor any of their employees, makes any warranty, express or implied, or assumes any legal liability or responsibility for the accuracy, completeness, or usefulness of any information, apparatus, product, or process disclosed, or represents that its use would not infringe privately owned rights. Reference herein to any specific commercial product, process, or service by trade name, trademark, manufacturer, or otherwise does not necessarily constitute or imply its endorsement, recommendation, or favoring by the United States Government or any agency thereof, or Battelle Memorial Institute. The views and opinions of authors expressed herein do not necessarily state or reflect those of the United States Government or any agency thereof.

\author{
PACIFIC NORTHWEST NATIONAL LABORATORY \\ operated by \\ BATTELLE \\ for the \\ UNITED STATES DEPARTMENT OF ENERGY \\ under Contract DE-AC05-76RL01830
}

Printed in the United States of America
Available to DOE and DOE contractors from the Office of Scientific and Technical Information,
P.O. Box 62, Oak Ridge, TN 37831-0062;
ph: (865) 576-8401
fax: $(865)$ 576-5728
email: reports@adonis.osti.gov

\begin{abstract}
Available to the public from the National Technical Information Service, U.S. Department of Commerce, 5285 Port Royal Rd., Springfield, VA 22161 ph: (800) 553-6847 fax: $(703) 605-6900$ email: orders@ntis.fedworld.gov online ordering: http://www.ntis.gov/ordering.htm
\end{abstract}

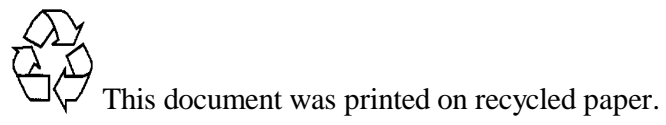




\title{
Summary of the Preliminary Optical ICHMI Design Study: A Preliminary Engineering Design Study for a Standpipe Viewport
}

\author{
NC Anheier Jr \\ EJ Berglin \\ HA Qiao \\ BK Hatchell
}

December 2013

Prepared for the U.S. Department of Energy under Contract DE-AC05-76RL01830

Pacific Northwest National Laboratory

Richland, Washington 99352 


\title{
Summary Report of the Preliminary Optical Access Design Study A Preliminary Engineering Design Study for a Standpipe Viewport
}

\author{
Deliverable: M4SR-14PN1301092 \\ In-vessel Optical Measurements for Advanced SMRs \\ PICS WP\# SR-14PN130109
}

November 2013

\section{Introduction}

This summary report examines an in-vessel optical access concept intended to support standoff optical instrumentation, control and human-machine interface (ICHMI) systems for future advanced small modular reactor (AdvSMR) applications. Optical-based measurement and sensing systems for AdvSMR applications have several key benefits over traditional instrumentation and control systems used to monitor reactor process parameters, such as temperature, flow rate, pressure, and coolant chemistry (Anheier et al. 2013). Direct and continuous visualization of the in-vessel components can be maintained using external cameras. Many optical sensing techniques can be performed remotely using open optical beam path configurations. Not only are in-vessel cables eliminated by these configurations, but also sensitive optical monitoring components (e.g., electronics, lasers, detectors, and cameras) can be placed outside the reactor vessel in the instrument vault, containment building, or other locations where temperatures and radiation levels are much lower. However, the extreme AdvSMR environment present challenges for optical access designs and optical materials.

Optical access is not provided in any commercial nuclear power plant or featured in any reactor design, although successful implementation of optical access has been demonstrated in test reactors (Arkani and Gharib 2009). This report outlines the key engineering considerations for an AdvSMR optical access concept. Strict American Society of Mechanical Engineers (ASME) construction codes must be followed for any U.S. nuclear facility component (ASME 2013); however, the scope of this study is to evaluate the preliminary engineering issues for this concept, rather than developing a nuclear-qualified design. In addition, this study does not consider accident design requirements.

In-vessel optical access using a standpipe viewport concept serves as a test case to explore the engineering challenges and performance requirements for sodium fast reactor (SFR) and hightemperature gas reactor (HTGR) AdvSMR applications. The expected environmental conditions for deployment are reviewed for both AdvSMR designs. Optical and mechanical materials that maximize component lifetime are evaluated for the standpipe viewport design under these conditions. Optical components and opto-mechanical designs that provide robust optical-tometal seals and stress-free optical component mounting are identified, and then key performance specifications are developed for a sapphire optical viewport concept. Design strategies are examined that protect the internal optical surfaces from liquid-coolant condensation and impurity deposits. Finally, a conceptual standpipe viewport design that is suggestive of how this concept could be assembled using standard nuclear-qualified pipe components, is presented. 


\section{Advanced Small Modular Reactor Design Detail}

The optical access concept is considered for only the SFR and HTGR AdvSMR designs, because these designs are relatively mature, and test reactors with these designs have been built and operated. Table 1 summarizes key operating parameters for the SFR and HTGR AdvSMR designs and compares them against typical operating conditions within boiling-water reactors (BWRs) and pressurized-water reactors (PWRs). The core inlet/outlet temperature, vessel pressure, power density, and thermal efficiency parameters are averages found in the references cited in Table 1. Although many specific operational characteristics of future AdvSMR concepts are somewhat unclear or are subject to change, the engineering design basis for optical access presented in this report is not expected to significantly change. All advanced reactor concepts are expected to operate at temperatures far above those found in current light water reactors (LWRs). Core outlet temperatures provide a sense for highest temperatures that in-vessel monitoring systems would be expected to tolerate. Pressure is a critical consideration when engineering optical pathways into the reactor vessel. SFR vessel pressures operate near atmospheric, while the HTGR operates near $7 \mathrm{MPa}$. Thermal efficiency describes the ability to convert thermal to electrical energy, and generally increases as a function of reactor temperature.

Published values for gamma and neutron flux in AdvSMR concepts often differed greatly. Flux (i.e., fluence rate) is the most useful way to characterize the neutron environment, because it can be used to estimate total dose over any period of time. It is important to also estimate the fluxes of both thermal and fast neutrons, but this information was not always available. For the purposes of this report, we extrapolated the gamma and average total neutron flux for the HTGR by scaling PWR maximum gamma and average total neutron flux (i.e., $10^{6} \mathrm{~Gy} / \mathrm{hr}, 5 \times 10^{13}$ $\mathrm{n} / \mathrm{cm}^{2} \cdot \mathrm{s}$ ) to core power density (Knoll 2000). Power density describes the amount of thermal energy generated per unit area of the reactor core. While not exact, this is a reasonable scaling estimation (Kolev 2011). More fissile material is required for SFR designs, which leads to a gamma and neutron flux roughly 10 times higher than this scaling estimate provides $^{(a)}$ as shown in Table 1.

(a) Richard Wood and David Holcomb, ORNL, personal communication, November 1, 2013. 
Table 1. Summary of Expected Reactor Operating Conditions

\begin{tabular}{|c|c|c|c|c|c|c|c|}
\hline $\begin{array}{c}\text { Reactor } \\
\text { Type }\end{array}$ & $\begin{array}{c}\text { Core } \\
\text { Inlet/Outlet } \\
\text { Temp. }\left({ }^{\circ} \mathrm{C}\right)\end{array}$ & $\begin{array}{l}\text { Vessel } \\
\text { Pressure } \\
\text { (MPa) }\end{array}$ & $\begin{array}{c}\text { Maximum } \\
\text { Gamma } \\
\text { Flux } \\
\text { (Gy/hr) }\end{array}$ & $\begin{array}{c}\text { Average } \\
\text { Total } \\
\text { Neutron Flux } \\
\left(\mathrm{n} / \mathrm{cm}^{2} \cdot \mathrm{s}\right)\end{array}$ & $\begin{array}{c}\text { Power } \\
\text { Density } \\
\left(\mathrm{MWth} / \mathrm{m}^{3}\right)\end{array}$ & $\begin{array}{c}\text { Thermal } \\
\text { Efficiency } \\
(\%)\end{array}$ & References \\
\hline $\begin{array}{l}\text { BWR/ } \\
\text { PWR }\end{array}$ & $292 / 330$ & $7 / 15.5$ & $1 \times 10^{6}$ & $5 \times 10^{13}$ & $56 / 98$ & 34 & $\begin{array}{l}\text { Knoll (2000); } \\
\text { Westinghouse } \\
\text { (2002); Nelson } \\
\text { (2008); Ragheb } \\
\text { (2011) }\end{array}$ \\
\hline SFR & $500 / 550$ & $\sim$ Ambient & $6 \times 10^{4}$ & $2 \times 10^{15}$ & 350 & 36 & $\begin{array}{l}\text { Zrodnikov et al. } \\
\text { (2005); Hoffman et } \\
\text { al. (2006); Ragheb } \\
\text { (2011) }\end{array}$ \\
\hline HTGR & $450 / 750$ & 7 & $4 \times 10^{7}$ & $3 \times 10^{12}$ & 6 & 50 & $\begin{array}{l}\text { Potter and Shenoy } \\
\text { (1996); Moses } \\
\text { (2010) }\end{array}$ \\
\hline
\end{tabular}

BWR = boling-water reactor

HTGR - high-temperature gas reactor

PWR = pressurized-water reactor

SFR = sodium fast reactor

Figure 1 provides temperature and radiation flux estimates for SFR and HTGR designs at full power; however, actual values will vary significantly depending on the location and distance relative to the reactor vessel head. For SFRs, the cover gas cooling system maintains the reactor vessel temperature under normal operations. Neither the cover gas nor the vessel temperature is expected to significantly change with reactor power level. The top of the reactor vessel head is expected to reach about $150^{\circ} \mathrm{C}$ under normal operation. The interior surfaces of the HTGR vessel head are well insulated to prevent the steel from overheating. The top of the vessel head is expected to reach between $200^{\circ} \mathrm{C}$ to $370^{\circ} \mathrm{C}$ under normal operation. ${ }^{\text {(a) }}$ Figure 1 also depicts the standpipe viewport temperature conditions. This is discussed in further detail later in this report. Outside the core region, it is expected that the neutron flux will drop quickly. Gamma flux will be high near the core, but also can remain high in SFR designs further from the core because of sodium activation. The design requirements for the standpipe viewport components will clearly depend on the specific location within the reactor. The SFR standpipe location is most feasible mounted to the reactor vessel head, while the HTGR location could be much closer to the core.

(a) David Holcomb, ORNL, personal communication, November 4, 2013. 


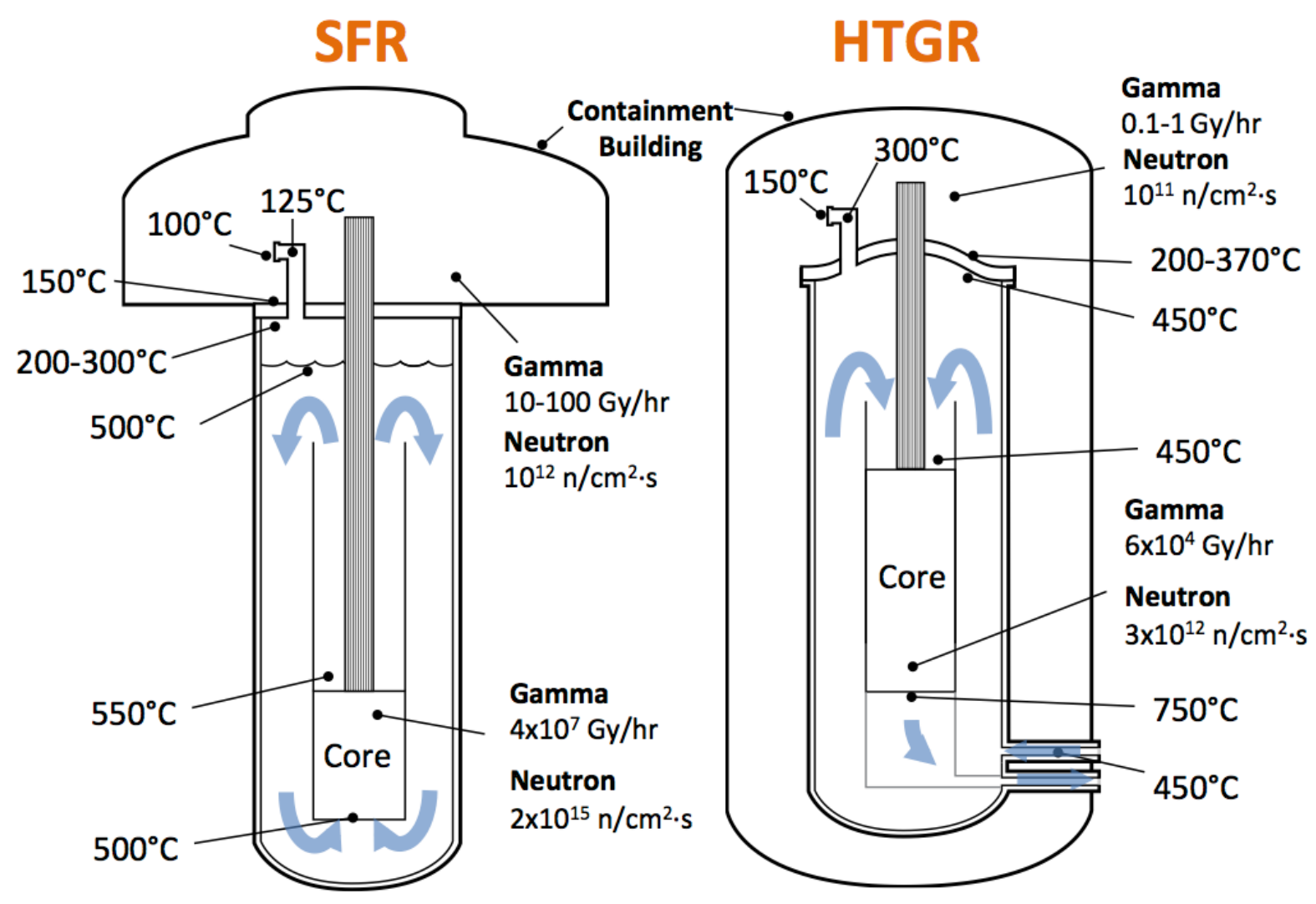

Figure 1. Estimated Temperature and Radiation Distributions for SFR and HTGR Designs

\section{Engineering Concept for In-vessel Optical Access}

In this section, the preliminary engineering design considerations of a standpipe viewport concept are introduced. Several other optical access concepts are also envisioned, but not included in this assessment. These other concepts include optical window ports, fiber-optic feedthroughs, and optical periscope modules. Many of the design conclusions for the standpipe viewport study will likely be relevant to these concepts. The viewport concept provides an optical path through which moving parts may be viewed, core inlets/outlets may be monitored, and metal surfaces may be inspected for cracking or swelling. Both passive and active remote sensing can be performed by many different optical sensing techniques. Standoff optical sensing will also help to isolate sensitive components from high in-vessel temperatures and radiation exposure, because sophisticated electro-optical systems, having for example an optical source, detectors, electronics, and other active and passive components, are unlikely to survive for useful durations within the in-vessel environment.

The goal of this study is to explore the optical access concept, identify the key engineering challenges, and examine potential solutions that could improve the concept feasibility. A sustained research, development, and demonstration (RD\&D) effort will be required to develop and certify complete engineering solutions that provide reactor vessel optical access. This engineering effort will be a significant challenge because of AdvSMR extreme environments. 


\section{Standpipe Viewport Concept}

The standpipe viewport concept, shown in Figure 2, is perhaps the most feasible approach that could be integrated within an AdvSMR design in the near-term future. Standpipes are routinely used in reactor vessel designs to elevate sensors, hardware, and electrical feedthroughs above regions of very high temperature and radiation. Standpipes for optical access into open test reactors have been used in the Tehran Research Reactor and demonstrated for long-term Cherenkov power monitoring (Arkani and Gharib 2009).
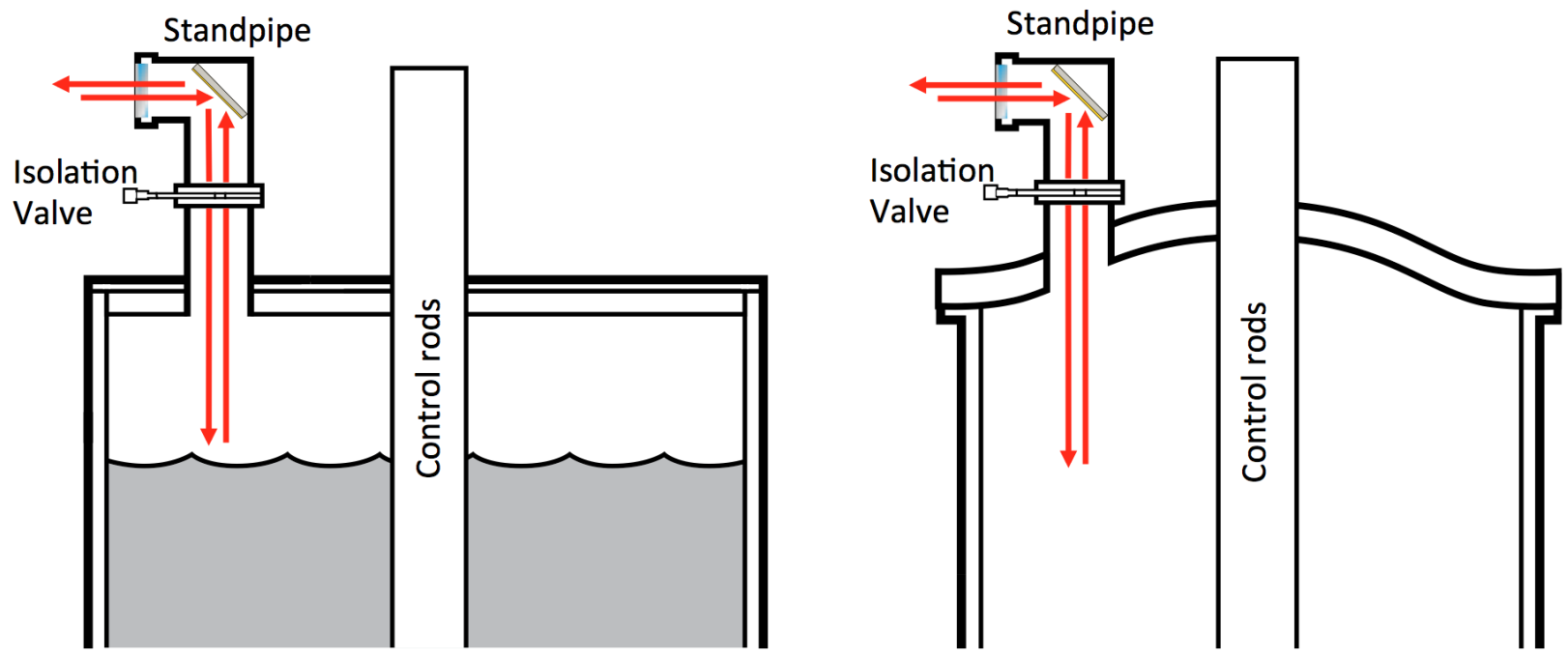

Figure 2. Upper Regions of a Sodium-Cooled (left) and Gas-Cooled (right) Reactor, Showing Optical Access Concepts. Optical access through the containment vessel also may be required.

The proposed design concept consists of a conventional standpipe assembly that supports the optical viewport and the right-angle metal mirror. In SFR designs, all penetrations into the reactor vessel, including standpipes, are through the top primary vessel head. Alternatively, gas-cooled reactors could place the standpipe at more convenient locations, such as the bottom of the vessel, to provide better accessibility to the intake plenum. In both arrangements, the temperature and radiation conditions are much lower compared to near-core regions. This design analysis considers only a standpipe welded directly to the reactor vessel head.

The optical components include a viewport window and an internal right-angle metal mirror that directs the optical beam path into and out of the reactor vessel. The right-angle mirror reduces the radiation-induced damage to the viewport window from direct line-of-sight gamma rays emitted from the core. A method is needed to minimize vapor, mist, impurity, and debris deposition on the internal optical surface. An external optical assembly could be used to scan or steer the reflected probe beam to the in-vessel target. The same system could be used to compensate for beam steering because of standpipe thermal expansion. A small retroreflector could be used to sample a portion of the reflected light and direct it back to a position-sensitive detector. The detection signal is processed to generate a beam steering error signal that locks the probe beam onto the target area. The standpipe metal components are selected based on coolant-specific corrosion control requirements. An isolation valve (shown in Figure 2) could be 
used to isolate the optical viewport components when in-vessel access is not required. Additionally, the isolation valve could close automatically in the event of a reactor upset. The internal diameter of the standpipe is sized to accommodate the field-of-view requirements for the intended application.

Feasible standpipe viewport designs must accommodate temperature ramps from reactor cold start and high continuous operating temperature, while surviving design-basis accident scenarios. Figure 1 shows the expected temperatures of the standpipe viewport and reactor vessel head regions under normal operation. The temperature of the standpipe viewport assembly will be lower than the top of reactor vessel head, because of convective and thermal radiation losses to the containment-building atmosphere. It is assumed that the interior and exterior of the SFR standpipe viewport will be $125^{\circ} \mathrm{C}$ and $100^{\circ} \mathrm{C}$, respectively, under normal fullpower operation. It is also assumed that the interior and exterior of the HTGR standpipe viewport will be $300^{\circ} \mathrm{C}$ and $150^{\circ} \mathrm{C}$, respectively, under normal full-power operation.

Metal and optical components must be selected with high mechanical strength to withstand high pressure (i.e., HTGR), vibration, and stress/strain. Durable optical-to-metal sealing concepts, using materials that mitigate differential thermal expansion, are required to minimize mechanical forces on the optical viewport window. Optical components must be selected that have radiation-resistant properties to provide long-term deployment under continuous gamma and neutron radiation exposure. Nominal neutron flux exposure to optical and mechanical standpipe components are estimated to be on the order of $10^{12} \mathrm{n} / \mathrm{cm}^{2} \mathrm{~s}$ for SFRs and $10^{11} \mathrm{n} / \mathrm{cm}^{2} \mathrm{~s}$ for HTGRs. The gamma flux is expected at $\leq 100 \mathrm{~Gy} / \mathrm{hr}$ for SFRs and $\leq 1 \mathrm{~Gy} / \mathrm{hr}$ for HTGRs.

\section{Optical Windows}

Several optical window materials, including chemical vapor deposited (CVD) diamond, ALON ${ }^{\circledR}$, spinel, sapphire, and fused silica, were identified to have high technical readiness for the standpipe viewport application (Anheier et al. 2013). The technical readiness was evaluated in terms of optical, thermal, structural, and chemical compatibility properties and radiation resistivity of these materials for near reactor vessel head (lid) applications. Optical window selection for a viewport design is also dependent on cost, commercial availability, and other factors. The commercial-off-the-shelf (COTS) availability of CVD diamond, sapphire, and fused silica optical windows is very high, with many sizes and grades available from stock. ALON and spinel windows have limited COTS availability and are generally fabricated to order. CVD diamond, sapphire, and fused silica windows can all be joined to metal flanges using various mounting techniques to create hermetic seals. The relative market costs for uncoated 50.8-mm diameter COTS fused silica and sapphire windows are roughly $\$ 175$ and $\$ 300$, respectively (i.e., Edmund Optics, http://edmundoptics.com, 11/10/2013). The CVD diamond window costs are strongly dependent on diameter (e.g., 8-mm/ $\$ 575,10-\mathrm{mm} / \$ 1000,25.4-\mathrm{mm} / \$ 11,000$; II-VI Advanced Materials Development Center, http://www.iiviamdc.com/buy-CVD-diamondwindow/order-CVD-diamond-window.html, 11/10/2013). For high-pressure designs, the actual costs may be greater depending on the window thickness requirements.

Differential thermal expansion is a paramount design consideration for many viewport applications, because the primary viewport failure modes involve loss of seal integrity and window failure due to differential thermal expansion between the metal viewport flange, the 
immediate seal material, and the window. Table 2 shows the thermal properties of each material compared to a 304 stainless steel flange material. Not only is sapphire an excellent choice for the viewport window, the coefficient of thermal expansion (CTE) is closest to 304 stainless steel.

Table 2. Summary of Thermal Properties

\begin{tabular}{|c|c|c|}
\hline Material & $\begin{array}{l}\mathrm{CTE}\left(\mathrm{ppm} /{ }^{\circ} \mathrm{C}\right) \\
@ 100^{\circ} \mathrm{C}\end{array}$ & $\begin{array}{c}\text { Thermal Conductivity }(\mathrm{W} / \mathrm{m} \cdot \mathrm{K}) \\
@ 100^{\circ} \mathrm{C}\end{array}$ \\
\hline 304 Stainless steel & 16.90 & 16.90 \\
\hline CVD diamond & 1.75 & 1500.00 \\
\hline Sapphire & 7.70 & 25.10 \\
\hline Fused silica & 0.57 & 1.46 \\
\hline
\end{tabular}

Sapphire has a melting temperature near $2040^{\circ} \mathrm{C}$, has superior stiffness, and has excellent mechanical wear properties. This material is chemically inert and insoluble in most solvents and acids. This optical material exhibits no measureable optical absorption under intense gamma radiation exposure up to doses of $10^{8} \mathrm{~Gy}$ (Islamov et al. 2007), while neutron fluence up to $10^{20} \mathrm{n} / \mathrm{cm}^{2}$ induced a number of absorption bands only at $\leq 450 \mathrm{~nm}$. This radiation-resistance figure should provide years of service before the onset of any noticeable optical absorption features. Thin sapphire viewport windows can be used, because the 448-MPa rupture modulus provides a significant failure safety margin even for HTGR pressure vessels.

\section{Optical Mirrors}

A prior report (Anheier et al. 2013) identified molybdenum, tungsten, and rhodium mirrors as excellent candidates for AdvSMR applications, because of their extremely high radiationresistance and mechanical durability. Custom tungsten and rhodium mirrors are available from several vendors; however, molybdenum mirrors are COTS items. Polished molybdenum mirrors are normally used for $\mathrm{CO}_{2}$ laser applications, because of the high reflectance $(98 \%)$ at $10.6 \mu \mathrm{m}$. The durability and radiation-resistance properties of molybdenum mirrors are somewhat offset by the low reflectivity at visible wavelengths (i.e., $55 \%-65 \%$ at $45^{\circ}$ incidence). Molybdenum has low thermal expansion, resulting in low optical distortion through large temperature differentials. Custom molybdenum mirrors can be fabricated with integral mounting features, because molybdenum can be machined, drilled, and tapped.

Gold-, silver-, and aluminum-coated mirrors are much more common COTS optical components and have significantly better broadband reflectivity. Broadband metallic mirror coatings are available with continuous temperature specifications that exceed the requirements for the AdvSMR standpipe concept. Metallic mirror coatings are known to lose reflectivity under intense radiation exposure, but the lifetime should be long under the modest standpipe flux conditions. It is possible that metallic mirror coatings could be applied to a machinable, robust substrate, such as molybdenum, to improve reflectivity at visible wavelengths. 


\section{Optical Window Viewport Design Considerations}

In this section, bonding and sealing methods are considered for sapphire window viewport designs. Several window viewport construction methods have been evaluated in detail, using brazing, O-ring, metal sealing ring, gasket, and adhesive sealing techniques (Bates 2011). Some of these techniques are potentially feasible for AdvSMR optical viewport engineering designs. The following provides a brief introduction, design considerations, and the potential AdvSMR design feasibility for each approach.

\section{Brazing}

The most common commercial solution for sapphire viewports is optical-to-metal brazing. Brazed sapphire viewports are available as COTS products that can usually sustain operation temperatures up to $450^{\circ} \mathrm{C}$ and pressures up to tens of MPa. Brazed seal designs do not rely on compressional forces to form the hermitic seal. Custom designs may even provide greater performance. While the specific brazing detail is generally a protected proprietary process, basic engineering and fabrication guidelines are available.

Sapphire brazing can be performed by active brazing at elevated temperatures in an inert atmosphere or in vacuum. Brazing alloys are based on silver or silver-copper alloys and contain titanium in varying concentrations. In active brazing, the melted brazing alloy readily bonds directly to the sapphire and metal viewport flange surfaces to form a hermitic seal. The brazing alloy must be selected with a CTE between the metal and the sapphire, because the bonding temperatures occur above $850^{\circ} \mathrm{C}$.

Conventional brazing (non-active) is another bonding technique used for optical materials such as sapphire. This technique uses a multi-step pre-metallization process to deposit intermediate metal film layers to the bonding areas of the window. Two pre-metallization processes are offered commercially. The first uses physical vapor deposition to deposit a thin titanium layer, followed by a chromium layer. The metallization layer is then nickel-electroplated. The other commercial technique uses a thermally activated diffusion/chemical conversion process in wet hydrogen gas called the Mo-Mn process. This process forms an oxide/metal composite, which bonds to the sapphire surface. The metallization layer is also nickel-electroplated.

The metal viewport flange must have a CTE nearly matched with sapphire so that the brazed joint can sustain full temperature cycling without failure. For this reason, viewport windows are seldom brazed directly to a metal steel flange. An intermediate transition metal sleeve, with closely matching CTE, is brazed to sapphire and laser- or electron-beam welded to the stainless steel flange. Welded joints can better tolerate CTE mismatch, unlike brazed joints. The metal sleeve is flexible and is formed in a variety of shapes to accommodate differential expansion and contraction. Sapphire windows can be either active or conventionally brazed at the window edge or face. Figure 3 illustrates a typical bonding geometry between an edge-brazed sapphire window and a stainless steel viewport flange. A U-shaped transition sleeve is featured in this design. Material selection of the intermediate metal and brazing alloy also must be chemically compatible with AdvSMR coolants. Brazed viewport seals appear to be very feasible for AdvSMR viewport applications, because of their superior performance specifications and COTS availability for both ultra-high vacuum (UHV) and high-pressure applications. 


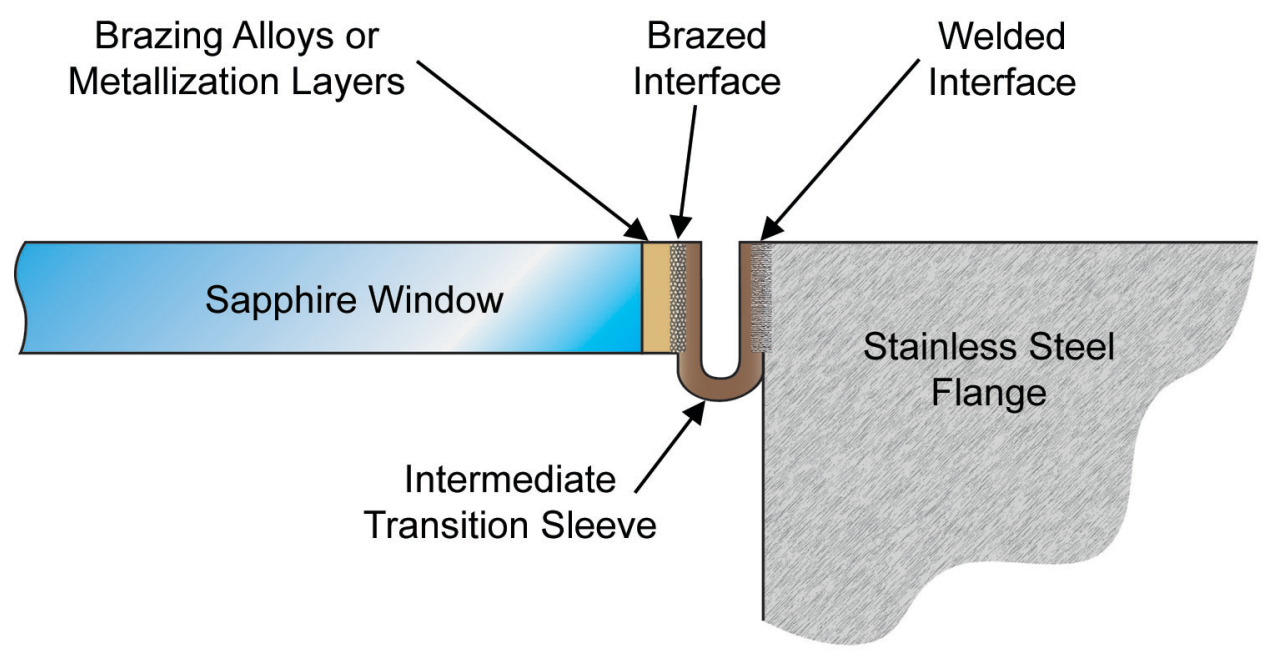

Figure 3. Key Design Details of a Sapphire Window Brazed Joint

\section{O-rings}

O-ring seals are another common design used for window viewports. O-rings are generally formed from elastomeric materials that conform to the surface to form a seal. O-ring seal designs are simple, inexpensive, and can be disassembled for maintenance and then resealed. O-ring seals can be designed for a wide range of pressure, temperature, and dimensional tolerance requirements. O-ring materials are available with high chemical, environmental, and abrasion-resistance properties. Most O-ring materials will degrade under exposure to ionizing radiation; however, some materials such as ethylene propylene diene monomer (EPDM) can sustain up to 5-MGy gamma irradiation and retain reasonable flexibility, strength, hardness, and compression (Lee 1985). Neutron irradiation at $7.2 \times 10^{8} \mathrm{n} / \mathrm{cm}^{2} \cdot \mathrm{s}$ produced a peak in EPDM crystallization at a neutron dosage of $10 \mathrm{KGy}$, although O-ring performance properties were not immediately correlated with crystallization in this study (Lambri et al. 2005). EPDM has an upper service temperature of $150^{\circ} \mathrm{C}$, so it is not suitable for HTGR viewport applications. In SFR applications, chemical compatibility of EPDM and other elastomers with sodium vapor or coolant impurities is unknown. In general, the feasibility of O-ring seals for AdvSMR applications is low, primarily because of the low working temperatures and questionable longterm radiation resistance and coolant compatibility of O-ring materials.

\section{Metal Sealing Rings}

Metal sealing rings have been developed for harsh environments where O-ring designs were not suitable. The sealing ring design and metal selection can be optimized depending on application requirements. Metal sealing rings are used for cryogenic, high-temperature (i.e., $>1000^{\circ} \mathrm{C}$ ), UHV, and high-pressure (i.e., $\leq 6900 \mathrm{MPa}$ ) applications. Metal rings are fatigueresistant and can provide good corrosion-resistance properties depending on the materials used in the design. The resilient spring design accommodates large temperature cycling. Metal rings can be made of copper, Inconel, stainless steel, and other alloys and can be electroplated with silver, cooper, indium, nickel, gold, lead, or other metals. The solid or hollow rings have a 
geometry (e.g., letter "C," letter "E," spring, or racetrack) that forms the seal. Metal rings are rarely used for glass and quartz window viewports because of the high compressive force required to form the seal; however, sapphire can easily withstand these forces. Figure 4 shows key design details of a sapphire viewport using a C-shaped metal sealing ring. The soft metal pads between the sapphire and metal serve to minimize localized stress caused by the clamping surfaces. Metal sealing rings appear to be very feasible for AdvSMR viewport applications, because of their superior performance specifications. COTS metal ring seals are even available from several vendors for nuclear applications.

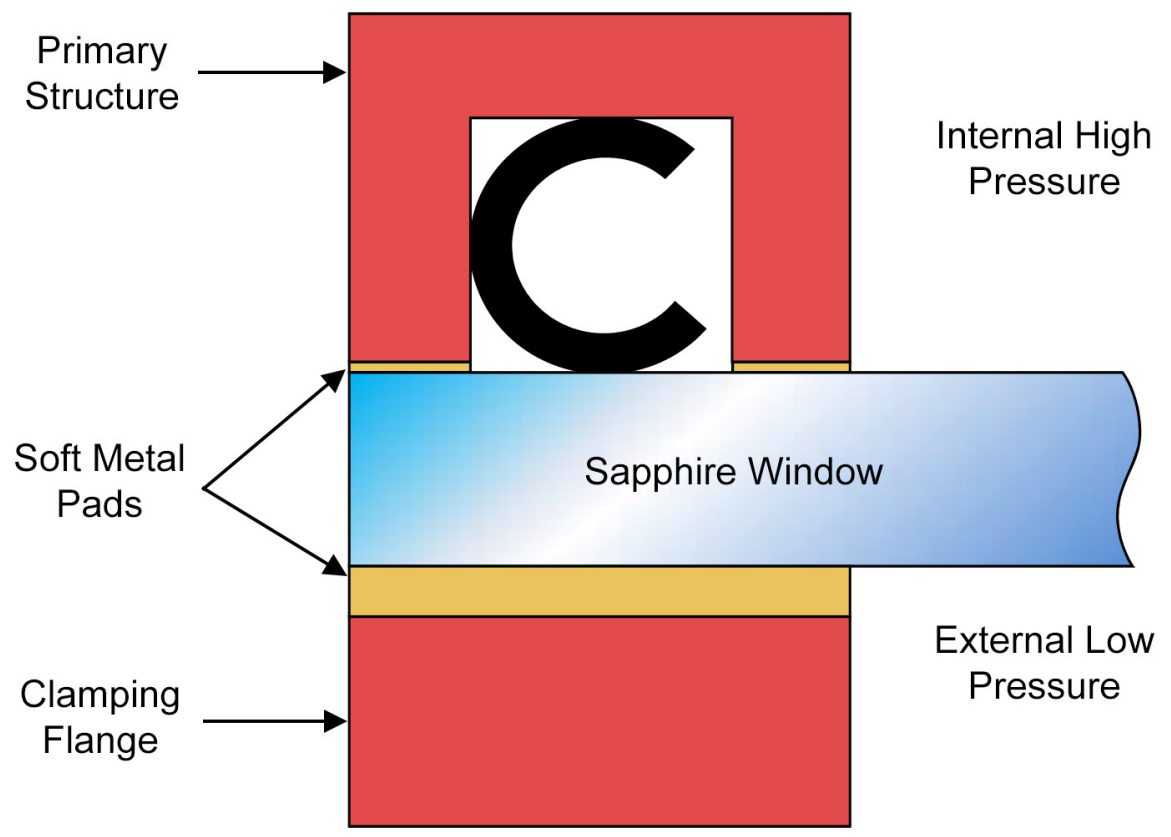

Figure 4. Cross-Sectional View Showing Key Design Details of a C-shaped Metal Sealing Ring

\section{Gaskets}

Gasket seals are commonly used in industrial applications. Gaskets are commonly made from paper, graphite, rubber, silicone, metal, cork, felt, neoprene, nitrile rubber, fiberglass, polytetrafluoroethylene, or a plastic polymer. The gasket forms a seal under a high compressive load (i.e., up to $14 \mathrm{MPa}$ ) using a bolted flange design. Sapphire windows with graphite gaskets have been used for high-temperature, low-pressure industrial applications. Gasket seals generally begin to leak over time and are not appropriate for high-pressure applications, making them poorly suited for AdvSMR viewport applications.

\section{Adhesives}

Optical windows can also be bonded to metal flanges using adhesives and epoxies, but these sealants generally do not wet or bond well to sapphire. Hard sealants are only useful for applications near room temperature. At elevated temperatures, the bond line generally fails from differential thermal expansion. Silicone is a soft sealant that does bond well to sapphire, 
but is limited to applications at $\leq 400^{\circ} \mathrm{C}$. Silicone also quickly degrades under ionizing radiation. No suitable adhesive materials were identified for AdvSMR optical viewports applications.

The techniques of brazing and metal rings seal design appear to be most feasible for AdvSMR viewport applications. Key requirements for a sapphire optical viewport are specified in Table 3 for both SFR and HTGR applications. In general, COTS sapphire viewport specifications, including maximum operating temperature, temperature differential, ramp rate, and maximum pressure, exceed the requirements for AdvSMR viewport applications. However, the viewport radiation performance and chemical compatibility are not specifications that vendors currently provide. Further testing, evaluation, and certification will be required before nuclear-qualified viewports could eventually become commercially available.

Table 3. Sapphire Optical Viewport Specifications

\begin{tabular}{|c|c|c|}
\hline Requirement & SFR & HTGR \\
\hline \multicolumn{3}{|c|}{ System Requirements } \\
\hline Operating Temperature $\left({ }^{\circ} \mathrm{C}\right)$ & 100 & 370 \\
\hline Normal Operating Temperature Differential $\left({ }^{\circ} \mathrm{C}\right)^{(\mathrm{a})}$ & 25 & 150 \\
\hline Temperature Ramp $\left({ }^{\circ} \mathrm{C} / \mathrm{min}\right)^{(\mathrm{b})}$ & \multicolumn{2}{|c|}{$1^{\circ} \mathrm{C} / \mathrm{min}$} \\
\hline Internal Pressure (MPa) & Ambien & 7 \\
\hline
\end{tabular}

\begin{tabular}{|c|c|}
\hline \multicolumn{2}{|c|}{ Window Requirements } \\
\hline Material & Grade 1 Sapphire \\
\hline Transmission Range $(\mu \mathrm{m})$ & 0.25 to 4 \\
\hline Clear Aperture $(\mathrm{mm})$ & $\geq 40$ \\
\hline Crystal Orientation $^{(\mathrm{c})}$ (degree) & 0 \\
\hline Parallelism (arm minutes) & $<3$ \\
\hline Flatness & $40 / 20$ \\
\hline Surface Finish & $\lambda / 4$ \\
\hline Chemical Compatibility (coolant and major impurities) & $\mathrm{HE}, \mathrm{CO}_{2}, \mathrm{H}_{2}, \mathrm{CH}_{4}$ \\
\hline Continuous Neutron Flux $\left(\mathrm{n} / \mathrm{cm}^{2} \mathrm{~s}\right)$ & $10^{11}$ \\
\hline Continuous Gamma Dose (Gy/hr) & $10-100$ \\
\hline \multicolumn{2}{|c|}{ Flange Requirements } \\
\hline Flange Material & 304 Stainless Steel \\
\hline Mounting Pipe & ANSI B16.5 Class 600 Flange, Pipe Size 2 \\
\hline Seal Design & Metal Brazing or Sealing Rings \\
\hline Leak Rate (std. cc/sec, He) & $1 \times 10^{-9}$ \\
\hline \multicolumn{2}{|c|}{$\begin{array}{l}\text { (a) Estimated difference between the inside and outside viewport window temperature. } \\
\text { (b) 10x engineering margin based on a PWR power/temperature rate ramp of } 0.1^{\circ} \mathrm{C} / \mathrm{min} \text { suggested by } \\
\text { the report: EPRI - Electric Power Research Institute. 1999. PWR Restart Ramp Rate Restrictions. TR- } \\
112140-\mathrm{V} 1 \text {, Electric Power Research Institute, Palo Alto, California. Available at } \\
\text { http://www.epri.com/abstracts/Pages/ProductAbstract.aspx?Productld=TR-112140- } \\
\text { V1\&Mode=downloadA. }\end{array}$} \\
\hline
\end{tabular}




\section{Mirror Mount}

Mirror opto-mechanical mounts must be designed to securely hold the mirror without introducing physical deformation. Stress or strain, from improper design, can deform the mirror shape and optical figure enough to change the reflected beam path direction. This can occur during mechanical mounting or by thermal-induced processes. If the mirror substrate is metal, direct mounting flanges can be machined into the substrate. This design omits tip/tilt adjusters and relies on the external optical assembly to steer the reflected probe beam to the in-vessel target. Internal stress can develop in metal mirrors as a result of casting, forging, and machining processes, and is generally relieved using a heat-treatment process at the time of manufacture. It is advisable to mount the mirrors at the elevated operational temperature to minimize stress induced by differential thermal expansion (Yoder Jr. 2005).

Four design principles have been documented to minimize physical stress (Zimmermann 1981):

- The mounting strain path should be isolated from the mirror surface. The maximum mount strain will usually occur at mounting screw threads or clamping locations. This strain should be isolated from the mirror surface by appropriate geometry.

- The mirror should be stiffer than the mount. This will allow loads to deform the mount rather than the mirror.

- The mirror optical surface should be configured to have proper shape after mounted and at operational temperature. This can be accomplished by simulating the optical surface figure under load and compensating during the optical fabrication process.

- The mounting surfaces should be flat and coplanar, with the same tolerances as the optical surface figure. This can be most readily achieved by diamond machining the mounting surfaces.

\section{Coolant and Impurity Condensation Mitigation}

In SFRs, sodium vapor and mist in cover gas tends to condense and deposit on reactor surfaces. It is likely the same condition will occur on the optical components within the standpipe. The bulk of sodium vapor behavior studies in cover gas were conducted for liquid metal fast breeder reactors (LMFBR) in the 1970s and 1980s (Himeno et al. 1976; Himeno 1979; Himeno and Takahashi 1980; Himeno et al. 1982). During this same period, various techniques including mesh-packed trap (Yamamoto and Suzuoki 1981), convection barrier, and drip receiver (Himeno et al. 1982) were evaluated to remove sodium mist from the cover gas. This research aimed to reduce sodium-metal build-up on reactor wall and component surfaces by filtering the cover gas as it passed through an external processing loop. Limited follow-up research in this area has been conducted since the 1980s. In these early studies, it was shown that sodium mist was formed and could be quickly (i.e., after 10 hours) collected in measureable quantities by inserting a collection apparatus into the reactor cover gas region (Himeno and Takahashi 1980). This short time frame will be problematic for the optical viewport concept, because the optical surfaces will quickly become coated with sodium. Another study also determined that the sodium mist size distribution was between $1.5 \mu \mathrm{m}$ and $13 \mu \mathrm{m}$ for a coolant 
pool temperature between $350^{\circ} \mathrm{C}$ and $520^{\circ} \mathrm{C}$. The mesh-packed traps, used in this study, are an unfeasible solution for the optical viewport design, because the trapping efficiency is at a minimum between 1 and $10 \mu \mathrm{m}$ (Yamamoto and Suzuoki 1981) and the trap would obstruct optical beam path through the standpipe.

A preliminary COTS and industry analysis that identified several technologies and methods that possibly could be adapted to mitigate or actively remove sodium vapor/mist deposits onto optical surfaces within the standpipe was conducted. Both the advantages and disadvantages for each technology and method are discussed in the following list. Combinations of these methods many be required to effectively mitigate the sodium vapor/mist deposition.

- Isolation Valve and Shutter: The concept of installing an isolation valve on the standpipe was presented earlier. Additionally, the isolation valve could close automatically in the event of a reactor upset or close during standpipe viewport maintenance. Roughly 155 vendors supply nuclear-certified valves worldwide (Skousen 2011). Viewports are often used in UHV systems to monitor internal processes. When used in a vacuum deposition system, viewports are typically equipped with rotary shutters to reduce deposition on the internal window surface. The shutter can be actuated using a magnetically coupled feedthrough and an external rotary drive system. A shutter is not a complete barrier to prevent sodium deposits, but will extend the service life of the mirror and window components. All-metal (usually stainless steel) viewport shutters and isolation valves are readily available from commercial UHV vendors. These components are designed to be baked up to $250^{\circ} \mathrm{C}$ to remove water layers on the internal vacuum surfaces. It is likely these designs could be adapted to the standpipe viewport concept. This is a simple solution, but only effective at preventing or reducing sodium deposits on the optical surfaces when closed.

- Wipers: At least one manufacturer makes an all-metal wiper for large digester vessel viewports. Customization may be needed for wiper blades that are compatible with the invessel environmental conditions. The wiper can be actuated using a magnetically coupled feedthrough and an external rotary drive system. This is a simple solution, but over time the optical surfaces will become damaged by the wiper. It is possible that the wiper must run continuously or at a reduced duty cycle to remove coolant vapor and impurity deposits. When operating, the wiper will interfere with the beam path through the standpipe.

- Optical Components at Controlled Temperature: Controlling the temperature of the optical components may reduce sodium condensation onto the window and mirror surfaces. Prior studies showed that sodium vapor and mist tended to condense onto in-vessel stainless steel surfaces having temperatures less than $100^{\circ} \mathrm{C}$ to $150^{\circ} \mathrm{C}$ (Himeno et al. 1982). Between $100^{\circ} \mathrm{C}$ and $250^{\circ} \mathrm{C}$, sodium condensation formed 5 - to 7 -mm-diameter liquid droplets. These large and finer droplets tended to accumulate and remain on the surface. However, when the surface temperature was above $250^{\circ} \mathrm{C}$, sodium condensed to form a thin liquid film, which becomes subject to gravitation forces. However, this sodium vapor condensation behavior changes depending on sodium wettability on optical material surfaces. A study on wettability of molybdenum metal by liquid sodium suggested a critical temperature of $160^{\circ} \mathrm{C}$, below which no wetting occurred (Addison and Iberson 1965). There was some evidence that ceramics, such as $\mathrm{Al}_{2} \mathrm{O}_{3}$, have less sodium wetting potential at 
higher temperature (i.e., $200^{\circ} \mathrm{C}$ ) (Addison 1984, p. 262). However at higher temperatures, the wetting behavior changes because of chemical reactions between liquid sodium and impurities. For example, when temperatures increased to between $277^{\circ} \mathrm{C}$ and $304^{\circ} \mathrm{C}$, an exothermic reaction occurs between the thin molybdenum oxide surface layer and sodium, producing a black powder that consists of molybdenum metal and a ternary oxide phase (Addison et al. 1965). It may be possible to select an optimum temperature range for each optical component that minimizes sodium condensation and chemical reactions.

- Purge Gas on Optics: An inert gas purge can be used to continuously blow gas tangentially across the optical surface to prevent sodium deposition. An argon gas purge method was used to minimize sodium condensation on a germanium window during a measurement of sodium emissivity (Jackson and Tong 1984). In addition, a deuterium gas purge was used to minimize carbon deposition on first mirrors in the International Thermonuclear Experimental Reactor (Litnovsky et al. 2009). This could be a viable method for AdvSMR viewport cleaning, but would consume and introduce a large quantity of highly purified gas into the reactor vessel.

- Laser Evaporation and Plasma Cleaning: Modeling and experimental studies of in-situ first surface mirror cleaning in fusion reactors demonstrated the ability to remove carbon deposition by laser ablation and laser heating using a yttrium aluminum garnet (YAG) laser (Semerok et al. 2007). Another study was effective at reducing $\sim 1-\mu \mathrm{m}$-thick beryllium depositions to approximately $10 \mathrm{~nm}$ after 40 laser pulses (Widdowson et al. 2011). Laser heating or ablation may be effective at removing sodium depositions; however, more research is needed to determine the feasibility of this approach. Research in tokamak reactors also demonstrated cleaning mirrors using plasma-induced chemical reactions (Litnovsky et al. 2007). However, AdvSMR cover gas purity and coolant contamination is a major concern; therefore, it is likely that introducing a chemical reaction-based method invessel would be unacceptable.

- Ultrasonic Cleaning: Ultrasonic cleaning is another well-known cleaning method that uses cavitation bubbles induced by ultrasonic energy. In a variation of the technique, an ultrasonic transducer can be attached to the optical component to generate continuous ultrasonic waves across the surface of the element. Ultrasonic-induced vibration has been demonstrated to minimize incrustation of heat exchanger surfaces using an ultrasonic transducer directly coupled to the heat exchanger tubes (Ashley 1974). In this application, the heat exchanger was vibrated in liquid below the threshold of cavitation, creating micro streams that move very rapidly and break up the boundary layer at the surface. Another study demonstrated that ultrasonic energy excited enough air molecules to dislodge residues on an imaging surface when the transducer was placed close to the surface (Maret 1978). It is possible that ultrasonic cleaning will be effective at diminishing the adhesion energy between deposited sodium and optical surfaces in the presence of argon cover gas. However, limited publication in this area makes it unclear whether this approach is feasible for AdvSMR applications. 


\section{Standpipe Metal Components}

The standpipe metal components are selected based on coolant-specific corrosion control requirements and compatibility with reactor vessel steel alloys. Caution should be exercised in design and construction involving dissimilar metals having different CTE values, although it is common to joint weld different steel alloys in pressure vessel applications. Many steel alloys are used in SFR and HTGR designs. HTGR reactor pressure vessel designs include $21 / 4 \mathrm{Cr}-1 \mathrm{Mo}$ and modified $9 \mathrm{Cr}-1$ Mo ferritic steels. Fe-Cr-Ni alloys, Hastelloys, and austenitic stainless steels are used for internal reactor components (Natesan et al. 2003). Sodium-cooled reactor vessels commonly use 304 and 316 stainless steel.

The metal components of a conceptual standpipe viewport design are shown in Figure 5. This concept suggests how a standpipe viewport could be assembled using standard nuclearqualified pipe components. The dimensions of the assembly were arbitrarily selected. A tee flange houses both the right-angle mirror and viewport assembly. Directly below the tee flange is a nuclear-qualified isolation valve. The standpipe is welded to the SFR head or other locations for the HTGR application, as discussed earlier in this report.
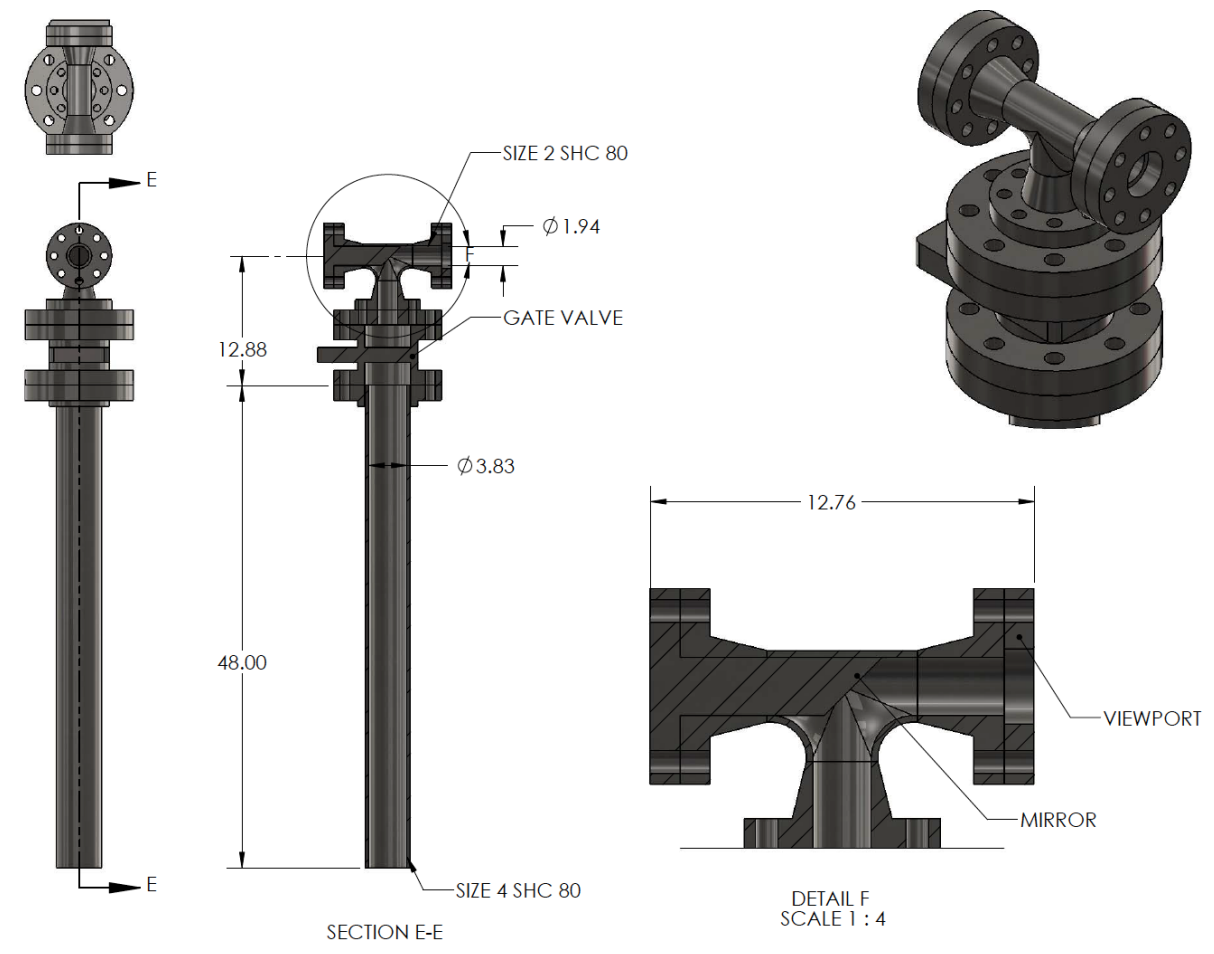

Figure 5. Standpipe Viewport Concept

\section{Summary}

This summary report examined key engineering considerations for a standpipe viewport concept. This concept is intended to support standoff optical ICHMI systems for future in-vessel 
AdvSMR monitoring and measurement applications. SFR and HTGR environmental conditions were estimated to establish the operational performance requirements of the standpipe viewport optical and mechanical components. While many optical materials were found suitable for the standpipe viewport concept, sapphire windows and molybdenum mirrors may provide a performance and COTS-availability advantage over other options. Brazed optical-to-metal seals and metal sealing rings were identified as feasible approaches for hermetically sealing sapphire to stainless steel. Both bonding methods are widely available from commercial vendors. Metal sealing rings are available for nuclear applications; however because of the extreme loading pressure required to form the seal, only high-strength optical materials can be used with this design. The engineering considerations for mirror mounts were also considered. Four engineering principles were provided to minimize conversion of mechanical mounting forces into mirror deformation. Design strategies were examined to protect the internal optical surfaces from liquid-coolant condensation and impurity deposits. Isolation valves and shutters are a simple solution, but are only effective at preventing or reducing these effects when closed. The feasibility of the other protection and cleaning methods must be determined by further study. Finally, a conceptual standpipe viewport design was presented that is suggestive of how this concept could be assembled using standard nuclear-qualified pipe components.

\section{References}

Addison CC. 1984. The Chemistry of the Liquid Alkali Metals. John Wiley \& Sons Ltd.

Addison CC, MG Barker, and RJ Pulham. 1965. "Reactions of Liquid Sodium with Transitionmetal Oxides. Part I. The Dioxides of Molybdenum, Tungsten, and Uranium." Journal of the Chemical Society, (Resumed) Paper 829:4483-4489.

Addison CC and E Iberson. 1965. "Liquid Metals. Part XI. The Wetting of Chromium, Molybdenum, and Tungsten by Liquid Sodium." Journal of the Chemical Society (Resumed), Paper 253:1437-1440.

Anheier NC, JD Suter, HA Qiao, ES Andersen, EJ Berglin, M Bliss, BD Cannon, R Devanathan, A Mendoza, and DM Sheen. 2013. Technical Readiness and Gaps Analysis of Commercial Optical Materials and Measurement Systems for Advanced Small Modular Reactors SMR/ICHMI/PNNL/TR-2013/04; PNNL-22622, Rev. 1, Pacific Northwest National Laboratory, Richland, Washington.

Arkani M and M Gharib. 2009. "Reactor Core Power Measurement Using Cherenkov Radiation and Its Application in Tehran Research Reactor." Annals of Nuclear Energy, 36:896-900.

Ashley MJ. 1974. "The Prevention of Deposition on Heat Transfer Surfaces by Ultrasonic Vibration." Birmingham University Chemical Engineer, 25(2):51-57.

ASME. 2013. 2013 ASME Boiler and Pressure Vessel Code, Section III: Rules for Construction of Nuclear Facility Components, Division 1 - Subsection NB Class 1 Components. American Society of Mechanical Engineers, New York.

Bates SC. 2011. Sapphire Viewports. NASA/CR-2011-215884. 
Himeno Y. 1979. "Sodium Vapor Deposition, on Simulated Model of LMFBR Rotating Shield Plug Annulus, (I)." Journal of Nuclear Science and Technology, 16(11):792-801.

Himeno Y and J Takahashi. 1980. "Sodium Mist Behavior in Cover Gas Space of LMFBR OutPile Experiment." Journal of Nuclear Science and Technology, 17(6):404-412.

Himeno Y, J Takahashi, K Yamamoto, K Mochizuki, and R Saito. 1976. Sodium Vapor Deposition in Annular Walls within Enclosed Argon Cover Gas Space. CONF-761218-1, Power Reactor and Nuclear Fuel Development Corporation, Yokyo, Japan.

Himeno Y, Y Yamagishi, and K Shiratani. 1982. "Effect of Barriers on Sodium Mist Deposition on LMFBR Components." Journal of Nuclear Science and Technology, 19(10):837-844.

Hoffman EA, WS Yang, and RN Hill. 2006. Preliminary Core Design Studies for the Advanced Burner Reactor over a Wide Range of Conversion Ratios. ANL-AFCl-177, Argonne National Laboratory, Argonne, Illinois. ADAMS Accession No. OSTI ID: 973480.

Islamov AK, EM Ibragimova, and I Nuritdinov. 2007. "Radiation-Optical Characteristics of Quartz Glass and Sapphire." Journal of Nuclear Materials, 362:222-226.

Jackson JD and D Tong. 1984. "Design and Development of a Sodium Pool Emittance Rig with Facilities for Mist Removal by a Steady Flow of Argon Purge Gas." British Nuclear Energy Society, 3:125-130.

Knoll GF. 2000. Radiation Detection and Measurement, Third Edition. John Wiley \& Sons, Hoboken, New Jersey.

Kolev NI. 2011. Multiphase Flow Dynamics 5: Nuclear Thermal Hydraulics, Second Edition. Springer-Verlag, Berlin Heidelberg.

Lambri OA, LM Salvatierra, FA Sánchez, CL Matteo, PA Sorichetti, and CA Celauro. 2005. "Crystal Growth in EPDM by Chemi-crystallisation as a Function of the Neutron Irradiation Dose and Flux Level." Nuclear Instruments and Methods in Physics Research Section B: Beam Interactions with Materials and Atoms, 237(3-4):550-562.

Lee G. 1985. "Radiation Resistance of Elastomers." IEEE Transactions on Nuclear Science, 32(5):3806-3808.

Litnovsky A, G De Temmerman, K Vukolov, P Wienhold, V Philipps, O Schmitz, U Samm, G Sergienko, P Oelhafen, M Büttner, I Orlovskiy, A Yastrebkov, U Breuer, and A Scholl. 2007. "Investigations of Single Crystal and Polycrystalline Metal Mirrors Under Erosion Conditions in TEXTOR." Fusion Engineering and Design, 82(2):123-132.

Litnovsky A, V Voitsenya, T Sugie, G De Temmerman, AE Costley, AJH Donné, KY Vukolov, I Orlovskiy, JN Brooks, JP Allain, V Kotov, A Semerok, P-Y Thro, T Akiyama, N Yoshida, T Tokunaga, and K Kawahata. 2009. "Progress in Research and Development of Mirrors for ITER Diagnostics." Nuclear Fusion, 49(7):075014.

Maret AR. 1978. "Ultrasonic Cleaning Apparatus for an Electrostatographic Reproducing Machine." Patent Number 4111546. 
Moses DL. 2010. Very High-Temperature Reactor ( VHTR) Proliferation Resistance and Physical Protection (PR\&PP). ORNL/TM-2010/163, Oak Ridge National Laboratory, Oak Ridge, Tennessee.

Natesan K, A Purohit, and SW Tam. 2003. Materials Behavior in HTGR Environments. NUREG/CR-6824, Argonne National Laboratory, Argonne, Illinois.

Nelson L. 2008. Boiling Water Reactor Basics. GE Global Research, Schenectady, New York. Potter RC and A Shenoy. 1996. Gas Turbine-Modular Helium Reactor (GT-MHR) Conceptual Design Description Report. Report No. 910720, Rev. 1, General Atomics, San Diego, California. GA Project No. 7658.

Ragheb M. 2011. Traveling Wave Reactor. Available at http://www.uxc.com/smr/Library/Design\%20Specific/TWR/Papers/2011\%20-\%20TWR.pdf.

Semerok A, SV Fomichev, JM Weulersse, F Brygo, PY Thro, and C Grisolia. 2007. "Heating and Ablation of Tokamak Graphite by Pulsed Nanosecond Nd-YAG Lasers." Journal of Applied Physics, 101(8):084916-084916-10.

Skousen PL. 2011. Valve Handbook, Third Edition. McGraw-Hill Professional, Blacklick, Ohio.

Westinghouse. 2002. IRIS (International Reactor Innovative and Secure) Plant Overview. Westinghouse Electric Co. Prepared for the IAEA Advanced Light Water Reactor Report.

Widdowson A, JP Coad, GD Temmerman, D Farcage, D Hole, D Ivanova, A Leontyev, M Rubel, A Semerok, A Schmidt, and PY Thro. 2011. "Removal of Beryllium-containing Films Deposited in JET from Mirror Surfaces by Laser Cleaning." Journal of Nuclear Materials, 415:S1199S1202.

Yamamoto H and A Suzuoki. 1981. "Investigation of Sodium Mist Trapping Efficiency in Meshpacked Trap." Journal of Nuclear Science and Technology, 18(11):870-877.

Yoder Jr. PR. 2005. Opto-Mechanical Systems Design, Third Edition. CRC Press.

Zimmermann J. 1981. "Strain-Free Mounting Techniques for Metal Mirrors." Optical Engineering, 20(2):187-189.

Zrodnikov AV, GI Toshinsky, OG Komlev, UG Dragunov, VS Stepanov, NN Klimov, II Kopytov, and VN Krushelnitsky. 2005. "Small Size Modular Fast Reactors in Large Scale Nuclear Power." In 18th International Conference on Structural Mechanics in Reactor Technology (SMiRT 18), pp. 4395-4406. August 7-12, 2005, Beijing, China. Paper SMiRT18-S01-1. 